\title{
Transporte público, mobilidade e planejamento urbano: contradições essenciais
}

\author{
MÁRCIO ROGÉRIO SILVEIRA ${ }^{I}$ \\ e RODRIGO GIRALDI COCCO ${ }^{I I}$
}

\section{Introdução}

A OCORRÊNCIA de manifestações populares nos meses de junho e julho de 2013, no Brasil, trouxe à tona, entre outros problemas, um recorrente que afeta as cidades brasileiras, qual seja, os preços das tarifas de transporte público coletivo, bem como a precariedade na prestação desse serviço. Nesse momento, mais do que nunca, parte da sociedade passou a questionar-se sobre quais são os problemas reais que acometem esse importante setor (transporte público coletivo), o qual é responsável pela produção e reprodução social ampliada da força de trabalho e pela sua produtividade.

A mobilidade proporcionada pelo transporte público facilita o aperfeiçoamento profissional contínuo das pessoas, o lazer, o acesso a equipamentos de saúde, centros culturais etc. Tarefa inglória, pois no Brasil, essa se dá em um ambiente construído absolutamente desadaptado para fazê-lo, seja porque os pactos de poder locais e regionais favorecem a expansão urbana dispersa, consoante uma proteção à produção imobiliária e ao rentismo - a despeito das diretrizes do Estatuto das Cidades e dos Planos Diretores Municipais -, seja porque o processo histórico que ensejara os serviços de transporte público no Brasil leva a marca do enfraquecimento contínuo do Estado no âmbito federal e dos entes federados, incluindo os municípios.

Entre outros fatores, isso decorreu em razão do esgotamento da capacidade de endividamento externo federal e delegação de responsabilidades aos municípios ( sem condições de levá-las a cabo); da ausência de canais para a alocação de recursos nesses municípios; da desestruturação dos órgãos de planejamento e gestão de transportes urbanos federais e estaduais; da formação de uma estrutura conservadora de poder com forte poder de persuasão, composta pelo empresariado de ônibus; e da força histórica das classes e frações de classes ligadas aos negócios de terra rural e urbana, presentes em pactos de poder de diferentes escalas.

Esses elementos combinados - somados a oscilações conjunturais dos preços dos fatores de produção do referido serviço, tais como mão de obra, com- 
bustível, renovação e manutenção de frota etc. - pressionam as tarifas para cima, em prejuízo dos usuários, e na maioria das cidades brasileiras ou os subsídios são muito baixos ou inexistentes. Isto é, o problema da eficiência econômica das empresas de transporte é solucionado pela fração de capital de transportes, muitas vezes em prejuízo da mobilidade em geral, segundo práticas de dilapidação da qualidade do serviço. Sempre a despeito dos sistemas de normas vigentes (que na maioria dos casos são muito frouxos).

Sem considerar esse contexto problemático, frações dos capitalistas brasileiros e os setores mais conservadores reclamam com relação à baixa produtividade de nossa força de trabalho. Procuram resolver isso através de altos índices de extração de mais-valia e, ao mesmo tempo, comparam o trabalhador brasileiro ao trabalhador estadunidense ou alemão, sem, no entanto - e tomados pela "miopia" de nosso capitalismo -, observar que devemos desenvolver os equipamentos de reprodução social ampliada para que essa produtividade do trabalho seja eficiente e comparada aos países desenvolvidos. ${ }^{1}$

Essa realidade é fruto de um descompasso nas políticas públicas: aumento da renda e do crédito para a aquisição de veículos individuais privados, sem uma correspondente política efetiva que imprima competitividade para os transportes públicos. Os equipamentos coletivos estão, portanto, aquém das necessidades das forças produtivas sociais. Eis o fio de Ariadne que liga os referidos protestos contra os aumentos das tarifas de transportes públicos, a fragilidade de nosso sistema público de saúde, o problema da educação e mesmo a questão da corrupção. Apesar de todos esses problemas serem concretos, sua percepção só se deu (principalmente ante a mídia) porque a classe média, engrossada nos últimos anos, é a que mais foi atingida com os nós de estrangulamentos que surgiram nessa nova fase de desenvolvimento econômico e, sobretudo, social no Brasil. Queremos dizer que foi somente antes da década de 1980 e com o governo Lula da Silva, após 2002, que nossa economia avançou de forma sustentável. Esse avanço vem ajudando na resolução de diversos problemas, o emprego, a renda, o crédito, a moradia, a miséria absoluta, e criou outros, como desigualdades na mobilidade e acessibilidade urbanas, na educação, na saúde e na segurança pública, por exemplo. Portanto, permitiu que percebêssemos melhor os velhos problemas que nos cercam.

Por outro lado, a mídia conservadora e dominante utiliza esses fatos para guindar novos "caçadores de marajás" e desestabilizar o governo, como se nós estivéssemos numa situação geral pior vis a vis os idos de 1994, sob o governo Fernando Henrique Cardoso. A falta de análises mais críticas sobre nossos reais problemas também é fruto de uma educação excessivamente técnica que tem formado quadros conservadores na estrutura dos seguimentos sociais médios. Um dos equívocos do governo Lula da Silva e Dilma Rousseff foi não ter incentivado da mesma forma os quadros de ciências humanas e sociais, principalmente os educadores, principais formadores de opinião. Além também do fato de 
ter faltado investimentos pesados em educação, saúde, segurança e mobilidade urbana e interurbana (vide o caso desastroso do Trem de Alta Velocidade). Outro ponto problemático refere-se à grande mídia, cuja regulação efetiva - que não é "controle", mas um conjunto de normas de atuação que incluem responsabilidade na divulgação de informações, evitando "assassinatos de reputação" sistemáticos etc. - mostra-se cada vez mais distante. Trata-se de uma iniciativa fundamental, a qual passa transversalmente pelo problema central em questão, ou seja, a mídia que controla os meios de comunicação de massa (um pequeno oligopólio de empresários), os setores mais conservadores (rentistas, por exemplo), o setor financeiro e alguns representantes dos interesses internacionais participam de um pacto de poder que divulgam análises, no que tange aos transportes públicos e demais equipamentos coletivos, na "tábula rasa", pois acobertam, por exemplo, entre outros, o empresariado de transportes, que participa deste pacto na escala regional e do município.

Fica claro que uma de nossas grandes deficiências é investir na produção e reprodução da força de trabalho com qualidade. No caso específico tratado neste artigo, nos equipamentos voltados aos deslocamentos cotidianos da força de trabalho - já formada, mas também em formação - na cidade. No tocante ao transporte público, é importante destacar que não apenas uma tarifa módica é necessária, mas também um sistema eficaz, que garanta a atração, por exemplo, de usuários de automóveis e, portanto, frações de classe que não utilizam diariamente o transporte público coletivo. E aí temos um nó górdio que em certa medida é o ponto de convergência de nosso famigerado "custo Brasil": as infraestruturas de transporte, pois em parte são elas que garantem a operação espacial eficaz desses serviços.

Até porque, trazer segmentos de classe de renda mais alta significa pôr em movimento uma retroalimentação positiva à eficiência econômica do setor, bem como a possibilidade de baratear as tarifas no quadro do sistema, reduzindo a necessidade de subsídios. Mas para levar a efeito essa tarefa, há que sobrepujar pactos de poder que se perpetuam nos municípios, sobretudo entre o capital imobiliário, os proprietários fundiários e rentistas e os empresários de transporte público por ônibus. Talvez em menor medida as associações comerciais, as quais têm também interesses muito próprios. Além disso, há o fenômeno da gentrificação (gentrification) de porções da cidade, nas quais se autosegregam os segmentos sociais de alta renda que, organizados em associações, se declaram abertamente contrários a políticas que toquem em seus interesses ou adentrem seu território, como a passagem de uma linha de metrô, trem etc. Urge sim, como veremos, criar condições não apenas para que o usuário pague uma tarifa justa ou em algumas condições não precise pagar, mas que ele tenha à sua disposição um serviço confiável, com certo conforto e eficácia cotidianamente, gerando um círculo virtuoso de atração de mais usuários.

Considerando a complexidade dessas questões, este breve artigo tem por objetivo principal discutir o cerne dos problemas que envolvem os transportes 
e a mobilidade cotidiana nas cidades brasileiras, trazendo à tona elementos que são negligenciados nas análises meramente técnicas, mas também nas análises políticas que embora tenham bandeiras legítimas de crítica social e denunciem problemas verossímeis, sua capacidade de realização é débil em razão de sua negligência em relação ao estudo da conjuntura, da formação social e do método marxista, que nada mais é do que um método para o planejamento e a ação sobre a realidade. Noutros termos, para auxiliar a correta compreensão da realidade e agir sobre ela contundentemente.

\section{Eficiência, eficácia e o papel do Estado na programação da mobilidade e da acessibilidade}

Uma tarifa justa de transporte público coletivo - a qual foi o mote das manifestações de junho e julho - é crucial para a realização da missão do serviço de transporte em uma sociedade desigual como a brasileira, que é garantir $\mathrm{o}$ acesso universal às oportunidades presentes na cidade, as quais contribuem para com o rompimento da reprodução intergeracional da pobreza mediante a oferta de empregos, aperfeiçoamento profissional, acesso à educação, aquisição de cultura geral etc. Além disso, uma parcela da renda cada vez maior dedicada ao pagamento de transporte (tarifas reajustadas acima da inflação) penaliza a população de baixa renda, o que significa que uma parcela menor dos recursos desse seguimento social é disponibilizada na aquisição de mercadorias-produto que mobilizam o efeito multiplicador interno e a geração de emprego e renda.

Exemplo disso ocorre na Região Metropolitana de São Paulo, mais especificamente na periferia metropolitana e áreas de contato entre o colar periurbano e rural. Nestes espaços, os moradores utilizam sobretudo o ônibus para seus deslocamentos cotidianos, e por se tratar de longas distâncias até o local de estudos e trabalho, comprometem um percentual maior de sua renda com transporte, cerca de $16,4 \%$, enquanto no interior são comprometidos $13,8 \%$ e no centro da capital, 15,9\% (Brasil, 2012). Vale ressaltar que na periferia metropolitana (incluindo áreas de favela) a renda da população é menor se comparada às demais áreas do estudo e, portanto, a renda dos segmentos sociais mais baixos é direcionada para o transporte.

Ademais, no caso brasileiro, o próprio acesso econômico ao transporte público - de suma importância para a população de cidades que "criam distância" continuamente - é bastante dificultado, em razão do que, no Brasil, em cidades com mais de 60 mil habitantes, $38 \%$ dos deslocamentos ainda são efetuados a pé, segundo pesquisa do Ipea (Brasil, 2012). Não porque haja proximidades urbanas planejadas, como ocorre em cidades europeias - pelo contrário, o cenário que se enseja é de uma paulatina expansão urbana dispersa em diferentes cidades -, mas porque seu acesso ao transporte é restrito pela tarifa e pela cobertura insuficiente da rede de transporte. No entanto, vale ressaltar que há outras questões. Por exemplo, o percentual de deslocamentos efetuados por transporte público no Brasil é de cerca de 32\%, e apenas 3\% deles é efetuado por sistemas sobre trilhos 
(trens urbanos, metrôs, bondes etc.) (Brasil, 2012), os quais operam sob maior eficácia, pois não sofrem interferência do trânsito. Ademais, as linhas de ônibus, em congestionamento, são ainda mais custosas em razão dos veículos "socorristas", os quais são postos em operação para evitar maiores atrasos.

Enquanto isso há um renascimento dos bondes (com diferentes denominações, como tramway, tranvía, funicular, VLT etc.) em todo o mundo, agora modernizados, sobre piso baixo (ampla e facilitada acessibilidade fisica) e design moderno. Por exemplo, a divisão de bondes da Alstom cresce a 10\% ao ano (dados de 2011), e na China há pelo menos quinze projetos envolvendo esse modal, o qual foi renovado em cidades como Paris, Bruxelas e Berlim. Isso, no entanto, não exclui o ônibus, importante para trajetos mais capilares, por exemplo, ou em horários em que os sistemas sobre trilhos são antieconômicos (como ocorre em Barcelona durante a madrugada).

O fato contundente é que o empresariado de transporte público por ônibus, mas também as encarroçadoras e fabricantes de chassis possuem forte poder de pressão. Em alguns congressos do setor pode-se observar um poderoso lobby que tende a desqualificar a aplicação de sistemas sobre trilhos (que pode ser combinada ao ônibus), vendendo a aplicação do BRT como solução unívoca. Ademais, poucas cidades e regiões brasileiras possuem efetivamente uma autarquia para o planejamento e a gestão dos transportes coletivos, para garantir a transparência contábil dos operadores privados de ônibus, sua justa remuneração e a qualidade do serviço para o usuário.

Destarte, o problema das tarifas exige uma reflexão mais aprofundada, ligada à eficácia do sistema, somada à capacidade de subsidiá-lo e regulá-lo, o que remete aos pactos de poder em diferentes escalas. Por outro lado, a luta pela tarifação zero do transporte público coletivo deixa o empresariado de transportes em uma situação relativamente cômoda, haja vista que não há, no presente momento, condições concretas de realização (condições políticas, institucionais e mesmo de alocação de recursos) desta proposta. Os idealizadores da proposta defendem o repasse total dos custos operacionais ao Estado ou aos rentistas e proprietários fundiários urbanos (IPTU), ou ainda, a setores da economia urbana como comércio, indústrias e serviços, mas sobretudo a estes últimos, considerados os maiores beneficiados pelo transporte público (que é o transporte de sua força de trabalho).

A premissa básica da proposta é descolar os custos fixos e variáveis do setor, da necessidade de tarifas pagas pelo usuário, tal como comumente ocorre com outros serviços urbanos públicos de remuneração indireta (saúde, educação pública etc.). Entretanto, sua implementação não é tão simples e seu sucesso depende de uma condição fiscal do Estado muito particular. $\mathrm{O}$ fato contundente é que o modelo não garante a eficácia operacional do sistema, que exige paulatinas inversões em novas infraestruturas; renovação e expansão de automotrizes; aplicação e desenvolvimento de tecnologia do estado da arte etc. Em São Paulo, 
tratar-se-ía de um custo de R \$ 6 bilhões anuais para a manutenção do sistema. Ressalte-se que durante o governo de Luiza Erundina (1989-1992) houve uma tentativa de implementação desse modelo na capital paulista, mas naquela ocasião, entendemos que se tocara em setores demasiado conservadores ao propor nova taxação sobre solo urbano, o qual remuneraria o sistema de transporte. Ademais, é necessário atrair o usuário do automóvel para o sistema (cuja repercussão retroage positivamente à subtração de veículos diariamente nas ruas) e isso só se opera com investimentos em eficácia, o que passa pelo aperfeiçoamento e expansão das infraestruturas, da intermodalidade, dos sistemas de informação ao usuário etc.

Assim, trata-se de efetuar uma distinção entre as possibilidades concretas e as possibilidades abstratas. As primeiras servem à tomada de decisões imediatas, as segundas, ao planejamento de médio e longo prazos. Em outras palavras, uma possibilidade concreta é a possibilidade para cuja realização podem ser reunidas, no momento presente, as condições para a sua realização efetiva, enquanto a possibilidade abstrata é definida pela ausência dessas condições, ao menos no momento presente (Cheptulin, 1982). A menos que possamos agir fora do quadro do sistema (do modo de produção hegemônico), as questões essenciais a serem atacadas de imediato referem-se ao:

- Fortalecimento das autarquias estatais associadas ao planejamento físico dos sistemas de transportes e sua fiscalização;

- Gestão contábil do capital de transportes e garantia de efetivação da Lei de Mobilidade Urbana;

- Canais para a alocação de recursos voltados à provisão de infraestrutura específica para transporte publico, como medida para aumentar a eficácia operacional do sistema de transporte;

- Provisão de intermodalidades com distintos modos e modais de transporte (incrementa a eficácia e retira um pouco de poder das famílias que monopolizam o transporte público por ônibus);

- Geração de condições para o aumento dos subsídios ao setor.

A necessidade de novíssimas infraestruturas, tais como corredores exclusivos e implementação e ampliação dos metrôs é notória e exibe-se em diferentes metrópoles brasileiras. A Fundação Dom Cabral, por exemplo, em estudo realizado em 2012, mostra que em realidades como a da Grande São Paulo, a cada ano, os congestionamentos aumentam 17\%, e na Grande Belo Horizonte e no Rio de Janeiro, cerca de 14\%. Isso se reflete diretamente nos tempos perdidos em congestionamentos. No Rio de Janeiro, a referida pesquisa apontou para um aumento de 1 h e 52 minutos para $2 \mathrm{~h}$ e 49 minutos de tempo em trânsito, e em São Paulo, 3h e 30 minutos por dia. Isso também repercute direta e indiretamente sobre a produção social de riqueza, haja vista o exemplo da capital paulista, onde se estimam perdas nos congestionamentos, na ordem de R $\$ 40$ bilhões ao ano em recursos. 
Vale ressaltar que os problemas dos transportes públicos não se resumem ao espaço da cidade. Há singularidades locais e regionais que são determinantes, mas sempre devem ser relacionadas ao cenário macroeconômico. No tocante aos sistemas de transporte público dos países europeus em crise, por exemplo, verifica-se forte pressão pelo aumento das tarifas e/ou redução dos subsídios, em razão da crise fiscal do Estado, das exigências dos credores da União Europeia (pressão neoliberal para a desestatização e redução dos direitos sociais, por exemplo) e da tendência de redução do IPK em razão dos altos níveis de desemprego e redução a dinâmica econômica (que corresponde a uma redução dos índices de mobilidade cotidiana).

No tocante ao problema brasileiro, perguntamo-nos: como proceder à melhora do quadro da mobilidade urbana em questão, quando se vê que décadas de rodoviarismo sedimentaram um forte empresariado de transportes por ônibus? Alheio a quaisquer inovações que agreguem outros modos de transporte em intermodalidade na cidade? $\mathrm{O}$ empresariado de transportes públicos por ônibus no Brasil congrega-se em uma classe organizada nacionalmente e com forte poder de pressão sobre os poderes públicos municipais, estaduais e quiçá o próprio governo federal.

Destarte, na medida em que seus interesses estão protegidos pela manutenção das permissões precárias de serviço (ou licitações para concessões com "cartas marcadas") - as quais não impingem claras obrigações para imput de tecnologia ou metas de eficácia para o serviço -, os usuários têm sua mobilidade e acessibilidade prejudicadas. A eficiência econômica desse capital, portanto, independe de sua eficácia operacional, haja vista que as práticas desse empresariado pautam-se, em muitos casos, por:

- Arrolamento de dívidas trabalhistas de trabalhadores do sistema;

- Intensificação da sucção de mais-valia dos motoristas e cobradores (levando a greves e paralisações sistemáticas, como tem ocorrido em Florianópolis e outras cidades brasileiras);

- Utilização de meios de produção já depreciados (ônibus usados), muitas vezes computados como novos;

- Redução de linhas, horários e veículos em operação em dias/itinerários mais rarefeitos etc.

Trata-se, portanto, de dificuldades associadas em parte às dificuldades do Estado para alocar recursos contínuos para o subsídio ao setor, para garantir instituições de planejamento, gestão e fiscalização, com poder de persuasão sobre o empresariado. Essas instituições devem garantir a correta mensuração de uma taxa de lucro adequada para o capital de transporte, recursos necessários à reinversão no sistema e as reais necessidades de subsídios. Vale ressaltar a característica especial desse serviço, cujo consumo refere-se a uma coletividade espacial e cuja eficácia depende, portanto, de uma distribuição racionalizada da população no espaço, a qual exige a presença do Estado sobre o planejamento urbano. 


\section{Planejamento urbano}

\section{e as estruturas conservadoras de poder do espaço urbano}

Como nos dizia o notável economista Ignácio Rangel (2005), no tocante ao projetamento econômico de Estado, aquilo que, na atividade de projetamento e planejamento depende do preço dos fatores de produção (de um projeto industrial, um serviço etc.), pode ser controlado e modificado pelo Estado. Esse pode, com as ferramentas das quais dispõe, modificar esses custos, em razão do que não são tão "paradigmáticos" para o problema em questão como dizem os liberais. Não estão na essência do problema embora tenham sua importância.

Por exemplo, no tocante aos custos variáveis e fixos das empresas de transporte público, recentemente fora sancionada a lei federal que baixara a zero a contribuição de PIS/Pasep e Cofins das empresas de transporte público, em parte por pressão das referidas manifestações ocorridas em junho/julho. Estima-se que pode haver redução de $4 \%$ dos custos das empresas e resultar em redução de até $15 \%$ no preço final das passagens. Além dessas medidas para desonerar a produção do serviço de transporte público, há possibilidades para viabilizar subsídios contínuos e provisão de infraestrutura especial (terminais, corredores exclusivos etc.). No tocante a esse problema, R\$ 1,7 bilhão em recursos do PAC foi disponibilizado para a abertura de nove corredores de ônibus na cidade de São Paulo, contabilizando $130 \mathrm{~km}$ de faixas exclusivas. Além disso, a prefeitura busca soluções para aumentar os subsídios contínuos ao setor, como a utilização de recursos da Cide (Contribuições de Intervenção no Domínio Econômico), ainda não discutidos com o governo federal.

Essas questões não estão na essência do problema, embora exerçam influência considerável. A questão é, quaisquer que sejam os modos/modais de transporte ou a combinação de modos de transportes, esses devem operar em um espaço organizado para tal, com densidades urbanas e teor social adequados para cada tipo de modo e modal escolhido. É, portanto, em grande medida, da inércia exercida pela organização do espaço sob a égide dessa formação social de que se trata.

E a grande dificuldade das cidades brasileiras é sobrepujar as estruturas de poder locais e regionais (mas com tentáculos na esfera federal) que exercem uma inércia sobre o planejamento da cidade. Noutros termos, realizar na sua plenitude a Lei de Mobilidade Urbana (a Lei Federal n.12.587/2012) e suas diretrizes dependerá da superação de uma série de entraves urbanos: a especulação urbana que mantém áreas intersticiais extensas; os processos de urbanização dispersa; os mecanismos de exceção dos planos diretores; as dificuldades em termos de custos públicos para desapropriações etc. Entendemos que é aqui que os aspectos particulares de nossa formação social se ligam contraditoriamente aos aspectos gerais do modo de produção capitalista: um capitalismo em franco desenvolvimento, que se deseja moderno, mas que debilmente investe na formação-manutenção de sua força de trabalho. Fazê-lo significaria ter que abrir mão de algumas per- 
manências arcaicas, como o caráter inalienável da propriedade privada da terra, a qual emperra, em certa medida, uma racionalização da mobilidade no espaço da cidade e repercute negativamente sobre o custo dessa mobilidade. Noutros termos, o problema pode ser entendido na chave das contradições entre as forças produtivas em ascensão e as relações de produção, porque a cidade é ela própria uma força produtiva, na medida em que aglomera com maior ou menor eficácia (facilita ou dificulta) a reprodução da força de trabalho. No entanto, há certas relações que permanecem na cidade que obstruem sua eficácia, seus efeitos úteis.

No caso brasileiro, da atualidade, podemos pensar no patrimonialismo, nas relações espúrias entre poder público local e grandes proprietários fundiários urbanos (que muitas vezes são também grandes proprietários rurais) e capitais imobiliários. Por outro lado, há as forças de urbanização dispersa que podem ser derivadas da especulação imobiliária (manutenção de vazios urbanos) por parte de proprietários fundiários urbanos, expulsando as populações mais pobres para as áreas perirurbanas, ou uma dispersão provocada pelo capital imobiliário. Sim, porque as relações de produção - capitalistas - que regem a incorporação, a viabilidade técnico-econômica, construção e comercialização podem, às vezes, ser obstruídas pelo instituto da propriedade privada da terra. Noutros casos, a produção capitalista imobiliária se vale deste mesmo instituto feudal para potencializar seus ganhos, mediante a valorização de áreas intersticiais à sua produção de imóveis. Há, portanto, uma dispersão dos ricos e uma dispersão dos pobres, ambas pressionando os custos de produção das redes de serviços públicos e sua eficácia para a população.

Esses problemas passam, notadamente, pela chave de discussão da formação social, pois as singularidades nas relações de produção, combinadas e sintetizadas nesta categoria-síntese (Sereni, 1972; Santos, 1978), conduzem a diferentes processos gerais, isto é, somente a atuação do Estado na estrutura econômica mais ampla não é suficiente para mitigar o problema em questão, se há um bloqueio ao salto qualitativo desejado em algum outro momento do processo.

No Brasil, nos vemos às voltas de um poderoso capital imobiliário - que não raro é sabotador dos planos diretores - que provoca urbanização dispersa e proprietários fundiários especuladores que emperram a provisão de infraestruturas, ou seja, o transporte público não consegue se antecipar ou ser implementado de modo concomitante à urbanização. Há diversos exemplos, inclusive, de situações onde a melhoria em acessibilidade física via infraestrutura de transportes (como o corredor Expresso Tiradentes em São Paulo) valorizou sobejamente o entorno (em cerca de 40\%), dificultando a permanência de famílias de menor renda. Esse é um aspecto importante do problema.

Por outro lado, uma desapropriação - por exemplo, para a ampliação do metrô de São Paulo - pode levar anos, não porque há uma discussão pública intensa a respeito (a qual, dependendo do grau de externalidades da obra, demanda 
tempo), mas em razão dos trâmites de implementação, morosidade jurídica e muitas vezes porque a linha programada passa por áreas centrais demasiadamente valorizadas e por pressão de associações de bairros de alta renda, de forte teor conservador (por vezes fascista). Vide o caso da "Linha 6 - Laranja" do metrô de São Paulo, cujo custo em indenizações é estimado em cerca de R\$ 700 milhões de reais. Ressalte-se que essa linha vem sendo idealizada desde 2008 e que, com esses imbróglios, só deve iniciar operação em 2020. Além disso, a continuidade da periferização da população e da taxa de urbanização dispersa, bem como o incremento de usuários ao sistema, pode tornar a obra obsoleta mesmo antes de sua operação. Vale destacar que, no contexto brasileiro, a implantação de infraestrutura urbana de transportes coletivos - como é o caso dos corredores de ônibus e da ampliação/implantação de sistemas sobre trilhos - envolve altos custos para a desapropriação, que se somam em: 1) Lucros cessantes (cálculo que envolve o que o proprietário deixou de lucrar com a desapropriação do imóvel); 2) Custos que envolvem rompimentos de contratos de trabalho e demais contratos que estavam em vigência (se se trata de um estabelecimento comercial ou industrial); 3) Valor de mercado do bem expropriado; 4) Juros moratórios e compensatórios; 5) Fundo de comércio, os custos de laudos, transportes, desinstalação etc.

No centro de grandes cidades, como Rio de Janeiro e São Paulo, esses custos podem representar cerca de um terço do custo total das obras, segundo especialistas no assunto. Esse é o preço pago pelo laissez-faire no qual se dá a organização espacial no espaço da cidade, deixado a bel prazer dos proprietários fundiários urbanos e dos capitais imobiliários. Daí a necessidade de um esforço contínuo pelo planejamento do uso do solo urbano, regulamentado em Plano Diretor, que possa coibir efetivamente edificações inadequadas à programação do Estado quanto à implementação de equipamentos e infraestruturas coletivas em rede, as mais afetadas pela distribuição espacial desigual da população.

\section{Considerações finais}

Haja vista o conjunto de condicionantes que foram debatidas neste artigo, o problema das tarifas de transporte público mostra-se muito mais um efeito do que uma causa dos problemas concretos, que vão desde a dificuldade em se planejar o espaço da cidade em favor da população e da racionalidade econômica do sistema de transporte; passando pelo problema dos subsídios aos serviços; a dificuldade em forçar o capital de transportes ao reinvestimento em qualidade e eficiência; e quiçá a própria distribuição de renda nacional e a relação entre o salário e o custo da cesta de reprodução social, que deve ser equilibrado. As dificuldades, na essência, se referem à resistência de estruturas conservadoras de poder - que não raro possuem acesso privilegiado ao poder público local - a um planejamento urbano que regule a inércia dos proprietários fundiários e a ação dos incorporadores e produtores imobiliários. Essas contradições entre forças produtivas em ascensão e relações de produção podem ser entendidas inclusive na superestrutura política das diferentes escalas de poder, isto é, nossa formação 
social é marcada por uma "modernização pela metade", na chave de uma "Revolução Prussiana", que repercute em diversos aspectos da vida nacional. Um dos elementos essenciais, portanto, é superar estes obstáculos que impedem a execução de políticas de teor mais moderno, em direção a um teor mais socialista do Estado e da sociedade.

Finalmente, o quadro deletério dos sistemas de transporte público no Brasil também nos mostra que há uma severa miopia das frações de capitais com relação ao movimento geral de acumulação do sistema capitalista, o que mostra a atualidade do método marxista - que é diferente do uso da "fraseologia" marxista, e do estudo de excertos isolados dos textos marxianos - para também explicar as contradições atuais. Ou seja, referenda a ideia de que cada capital particular de transportes - que também encerram em si, práticas arcaicas - atua, em muitos casos, segundo seus interesses particulares de acumulação, lançando mão de diferentes estratégias empresariais visando à sua eficiência econômica individual (logística empresarial, estratégias que se aproveitam da fragilidade dos contratos, aviltando a qualidade do serviço etc.), fato que pressupõe a ação do Estado enquanto planejador, gestor e fiscalizador deste setor, através de instituições que gerenciem o conjunto destes capitais que atuam na cidade, na região metropolitana etc. (logística de Estado).

Ao intensificar-se a circulação há aumento da acumulação capitalista. Fato que permite reger o território com custo-benefício social positivo à população. Obviamente que essa acumulação deve ser direcionada a remunerar o capital, mas também deve ser chamada a compor capitais, com o fito de investir nos setores mais carentes de investimentos. Essa discussão vai de encontro a todo o problema dos transportes na cidade, pois trata-se de gerir a eficácia da produção e da circulação de mercadorias, mediada pela força de trabalho, que também é reproduzida e que também circula enquanto mercadoria.

Ademais, esse planejamento dos transportes trata não apenas da edificação de infraestrutura, mas da criação de uma legislação urbana de uso do solo adequada (e sua execução, garantindo a diretriz da função social da terra urbana, presente no Estatuto das Cidades), um sistema tributário, uma formatação institucional etc., sendo a logística uma estratégia de gestão desse conjunto, voltada a tornar eficaz a fluidez territorial. Nesse caso específico, a fluidez dos deslocamentos cotidianos na cidade (logística urbana). Um passo importante nessa direção, como vimos reafirmando, é romper as estruturas conservadoras que se valem de seu acesso privilegiado ao poder político para bloquear o avanço das forças produtivas que desejam mais mobilidade.

\section{Nota}

1 Os hospitais, as escolas, as universidades e centros de ensino tecnológico e técnico, os equipamentos de lazer e de aquisição de cultura em geral como teatros, e de transportes públicos. 
Referências

BRASIL. Instituto de Pesquisas Econômicas Aplicadas (Ipea). Notícias. Brasília, 2012. Disponível em: <http://www.ipea.gov.br/portal/index>.

Fundação Dom Cabral. 2013. Disponível em: <http://www.fdc.org.br/pt/>.

CHEPTULIN, A. A dialética materialista: leis e categorias da dialética. São Paulo: Alfa-Ômega, 1982.

FENSTERSEIFER, J. E. Eficiência e eficácia no transporte público. Revista dos Transportes Públicos, São Paulo, n.34, p.7-85, 1986.

LOJKINE, J. O estado capitalista e a questão urbana. São Paulo: Martins Fontes, 1997.

LUKÁCS, G. A ontologia de Marx: questões metodológicas preliminares. In: Georg Lukács: Sociologia. São Paulo: Ática, 1981.

MARX, K.; ENGELS, F. Obras escolhidas. São Paulo: Alfa-Ômega, 1980.

RANGEL, I. Obras reunidas. Rio de Janeiro: Boitempo, 2005. 2v.

SANTOS, M. Sociedade e espaço: a formação social como teoria e como método. In: Espaço e Sociedade. Petrópolis: Vozes, 1978.

SERENI, E. La categoria "Formacion Economica y Social”. México: Ediciones Roca, 1972.

SILVEIRA, M. R. (Org.) Circulação, transportes e logística: diferentes perspectivas. São Paulo: Outras Expressões, 2011.

RESUMO - A essência dos problemas que acometem a mobilidade cotidiana nas cidades brasileiras remete à combinação de condicionantes históricas, como a manutenção de pactos de poder que aglutinam setores conservadores da sociedade. Nesses pactos convergem proprietários fundiários urbanos, promotores imobiliários que a eles se coligam e o próprio empresariado de transporte público. Esses, como lhes convêm, mantêm dissociados a eficiência econômica da eficácia dos serviços de transportes, mantendo seu equilíbrio contábil a despeito da qualidade do serviço. Nesse contexto, urgem novas infraestruturas, intermodalidades com novos modais de transporte urbano, políticas mais expressivas de subsídios, rigoroso planejamento do uso do solo, bem como uma atuação mais incisiva do Estado enquanto regulador, planejador e fiscalizador.

PALAVRAS-CHAVE: Transporte público, Mobilidade urbana, Acessibilidade, Planejamento urbano, Desenvolvimento.

ABSTRACT - The essence of the problems that affect the urban mobility in brazilian cities refers to the combination of historical conditions, such as maintaining pacts of power that coalesce reactionary sectors of society. These pacts converge urban land owners, developers that they met together and even entrepreneurs of public transport. These, as suit them, keep dissociated efficiency and effectiveness of transportation services, keeping your balance accounting despite the quality of service. In this context, it's essencial new infrastructures, intermodality with new modes of urban transport, subsidy policies 
more expressive, rigorous planning of land use, as well as a more incisive role of the State as regulator, planner and controller.

KETWORDS: Public transport, Urban mobility, Accessibility, Urban planning, Development.

Márcio Rogério Silveira é professor do curso de graduação em Geografia da Universidade Federal de Santa Catarina (UFSC) e do curso de Pós-Graduação em Geografia da mesma instituição. É coordenador do Grupo de Estudos em Desenvolvimento Regional e Infraestruturas (Gedri) e coordenador do Programa de Pós-Graduação em Geografia da UFSC. É também pesquisador do CNPq nível 2 (bolsista produtividade). @ - marcio.gedri@gmail.com

Rodrigo Giraldi Cocco é bolsista Capes pelo Programa de Doutorado Sandwich no Exterior (PDSE). @ - rodrigog.cocco@gmail.com

Recebido em $1^{\circ} \cdot 10.2013$ e aceito em 16.10.2013.

I Departamento de Geociências, Universidade Federal de Santa Catarina, Santa Catariana/SC, Brazil.

II Departamento de Geociências, Universidade Federal de Santa Catarina, Santa Catarina/SC, Brazil. 
